\title{
The influence of geologic structure on design and construction in a moderately deformed paleozoic sequence in Eastern Australia
}

\author{
Stephen Fityus \\ The School of Engineering, \\ The University of Newcastle, Newcastle, Australia
}

\author{
Ákos Török \\ Department of Construction Materials \\ and Engineering Geology, Budapest University of \\ Technology and Economics, Budapest
}

\author{
John Gibson \\ The School of Engineering, \\ The University of Newcastle, Newcastle, Australia
}

\begin{abstract}
This paper presents a case study to illustrate the role played by geologic structures in the design and construction of major transportation infrastructure, in a setting of moderately deformed Paleozoic sedimentary rocks in eastern Australia. It describes a complex development of folding, faulting and jointing that has resulted in significant inclination of beds, juxtaposition of strata and affected the weathering characteristics of a wide range of rock types. The sequence, which displays an upward transition from marine to terrestrial sediments, comprises an interbedded succession of conglomerate, sandstone, shale and erratic volcanics and crystal tuff. Unfavorable relationships between major excavation faces, inclined beds and jointing have resulted in problems with the stability of road cuttings. Also, the presence of faults and dykes at various scales has had a significant effect on weathering and rock strength. The paper demonstrates the importance of the choice of alignment at design stage, and how a basis of good structural interpretation and geologic mapping can be used to avoid problems during construction and issues with ongoing maintenance.
\end{abstract}

Key words: faulting, jointing, stability, weathering, volcanics, dykes, construction, design

\section{Introduction}

Moderately deformed sedimentary sequences are commonplace throughout the world. Such sequences underlie significant areas of the populated eastern margin of Australia. In the eastern Australian setting, the combination of moderately deformed hard and soft geologic units, and a temperate climate with

Address: $\quad$ S. Fityus, J. Gibson: Callaghan, Newcastle, Australia 2308, e-mail: Stephen.Fityus@newcastle.edu.au Á. Török: H-1111 Budapest, Stoczek u. 2, Hungary, e-mail:torokakos@mail.bme.hu Received: January 2, 2008; accepted: January 30, 2008 
an annual rainfall of $600-1500 \mathrm{~mm} /$ year, has produced a hilly topography with prominent peaks and geologically-controlled drainage patterns.

In response to continued economic growth and development, there is a program to construct a significant length of new motorway, to connect major economic, population and tourism centers along the eastern Australian seaboard. Much of this new infrastructure passes through moderately deformed Paleozoic sedimentary rocks. In many cases, alignments are constrained to more rugged terrain, to avoid the difficulties associated with acquiring and/or relocating existing developed areas. The increased construction difficulties in rugged terrains are accommodated by improvements in construction technology (i.e. tunnels, bridges and deeper road cuts); however, similar improvements in geotechnical investigation and design are also necessary to underpin more ambitious development proposals.

A recently reconstructed section of highway bypassed the small town of Karuah, near Newcastle, and so is locally referred to as the Karuah Bypass. A range of interesting engineering problems were encountered during construction, including a major bridge across a river filled with soft sediment, deposits of normally consolidated clay containing silcrete and soils and rocks with acid-sulfate potential. Many of these aspects have been discussed by Fityus et al. (2005) and will not be considered further in this presentation. This paper will focus on aspects of design and construction related to the local geologic structure and its subsequent influence on the properties of soils and rocks.

\section{Background}

\section{The Karuah Bypass}

The Karuah Bypass was constructed as part of a major upgrade of the Pacific Highway, to provide motorway conditions between the major cities of Sydney and Brisbane on the east coast. Construction of the Karuah Bypass commenced in 2002, and was completed by September 2004. It included the construction of $9.8 \mathrm{~km}$ of new divided carriageway, 2 major twin bridges (to cross the Karuah river and adjacent wetlands, respectively), 9 smaller bridges, 2 interchanges, and 10 major cuts and 10 fills, the largest cut being $27 \mathrm{~m}$ deep. It included the production of $100,000 \mathrm{~m}^{3}$ of Portland cement concrete (batched on-site), and $800,000 \mathrm{~m}^{3}$ of earthworks, of which $600,000 \mathrm{~m}^{3}$ required drilling and blasting. (Fityus et al. 2005)

Project design was undertaken on the basis of two geotechnical investigations: a preliminary investigation by Arup Geotechnics (ARUP 1999), and a detailed investigation by SMEC (SMEC 2002). In total, the investigations comprised 99 test pits and 103 drilled boreholes, with most including rock coring. 


\section{Geologic setting}

The area considered in this study lies within the broad geologic region of central-eastern Australia, which is generally referred to as the New England Fold Belt (NEFB) (Fig. 1). It is a sequence of sedimentary and volcanic units ranging in age from Late Devonian to Late Carboniferous (Carey and Browne 1938). It is more correctly described as the New England Orogen (Voisey 1959), although the more traditional term of Fold Belt will be retained here, because of its wider familiarity. Murray (1997) contends that the New England Orogen is the "easternmost element in the Tasman Orogenic Zone of eastern Australia, extending 1,500 km from Newcastle in the south to Bowen in the North".

The geology of the NEFB is lithologically and structurally complex. In its broader context, it contains a wide range of terrestrial and marine sedimentary rock types, deposited in a variety of gradational facies, intruded by several plutonic suites and overlain by younger volcanics. It is complicated by low to moderate deformation comprising gentle to tight folding and locally intense faulting of many types. The structure of the New England Province was redefined by Roberts et al. (1991), dividing it into a number of blocks: most notably the Tamworth Belt (Korsch and Harrington 1981) to the south and west (bounded by the Hunter-Mooki and Peel-Manning Faults); the Central Block through the central New England region and the north coast of New South Wales (NSW), and the Hastings Block of the mid-north coast of NSW.

The site discussed in this paper lies in the south-eastern extension of the Tamworth Belt, located within the Hunter Valley, where it has been further subdivided into 3 blocks; the Rouchel Block, to the west of the Karrakurra Fault, the Gresford Block between the Karrakurra and Williams River Faults, and the Myall Block between the Williams River Fault and the ocean (Fig. 1). A typical stratigraphic succession has been defined for each of these blocks, with the Myall Block being further differentiated into an eastern and a western succession.

\section{Site geology}

\section{Stratigraphy}

In a structural interpretation compiled by Scheiber (1998) and in a later compilation by the Geological Survey of New South Wales (GSNSW 2003), the area considered in this study is consigned to the western Myall Block, without further differentiation. This consignment was confirmed by Fityus et al. (2005), who mapped and interpreted the succession of the Karuah Bypass. The interpreted stratigraphic section of the Bypass is shown in Fig. 2.

Taking all of this into account, this study recognizes the massive purple beds of sandstone as the Karuah Sandstone, and thus consigning the Karuah Bypass section to span the interval from the Johnson's Creek conglomerate to the Karuah Formation, and including the Booral and McInnes Formations. In summary, the 


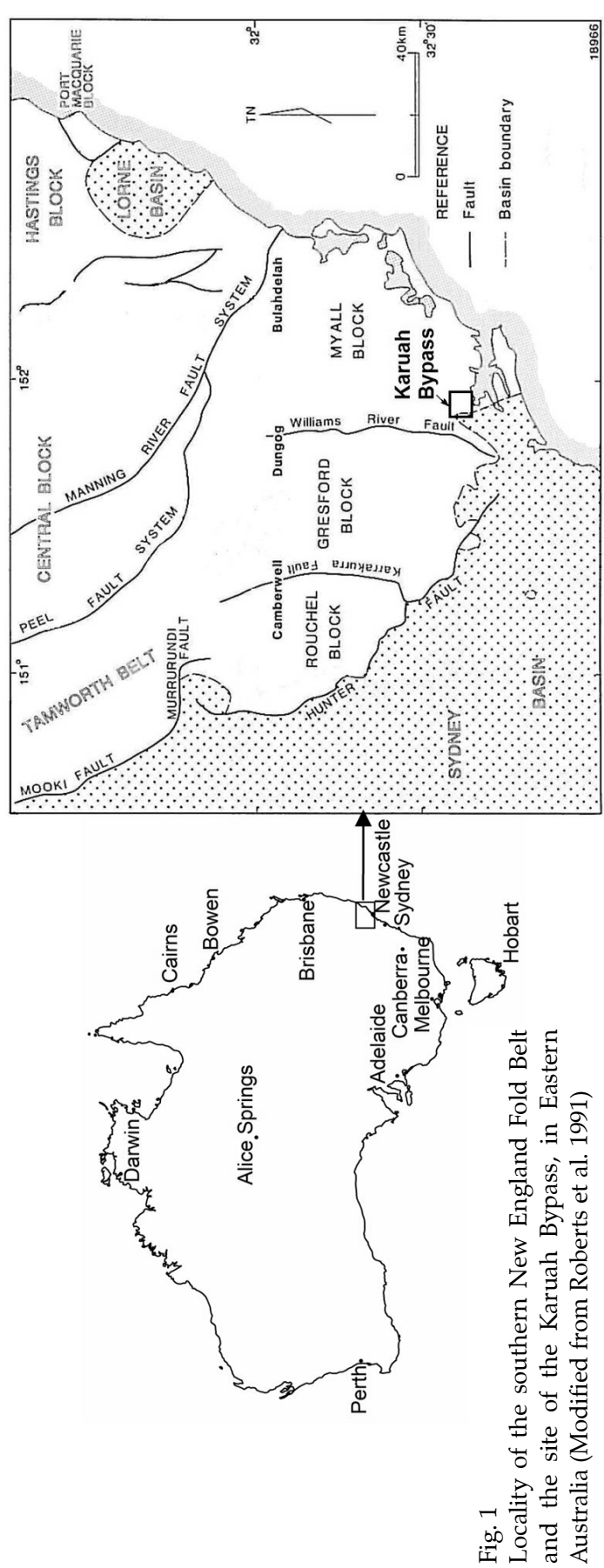

formations of the Karuah Bypass section are described below.

Karuah Formation

The basal units of the Karuah Formation are unlikely to be present within the Karuah Bypass works, as the unit is considered to be in faulted contact with the older Nerong Volcanics. The top of the Karuah Formation has been taken as a thin $(<10 \mathrm{~m})$, pink, felsic ignimbrite. Although this unit was not exposed during construction, it caps many of the steep-sided hills and ridges east of the river. The thick-bedded (Karuah) sandstone (up to $8 \mathrm{~m}$ ) that comprises most of the Karuah Formation is uniformly medium to coarse-grained, very well sorted, and conspicuously purple to oxide red in color. It is probably a beach deposit, based on its low angle crossbeds and textural maturity.

\section{Booral Formation}

The 800 m-thick Booral Formation is a more diverse unit than the underlying Karuah Formation. While dominated by medium to fine-grained gray feldspathic sandstone, it also contains significant units of tuff, siliceous mudstone and siltstone, with erratics of pebbly sandstone and conglomerate, the latter usually occurring as lenses. Occasional thin carbonaceous beds and laminations are present, ranging in thickness from centimeters to decimeters. Also 


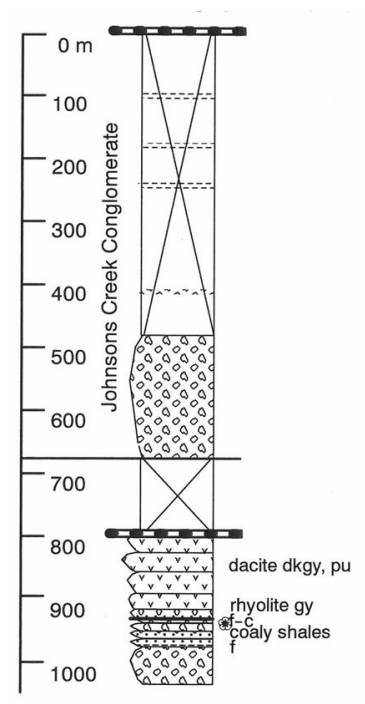

$\begin{array}{ll}\text { colour } & \\ \text { gy } & \text { grey } \\ \text { gn } & \text { green } \\ \text { pk } & \text { pink } \\ \text { pu } & \text { purple }\end{array}$
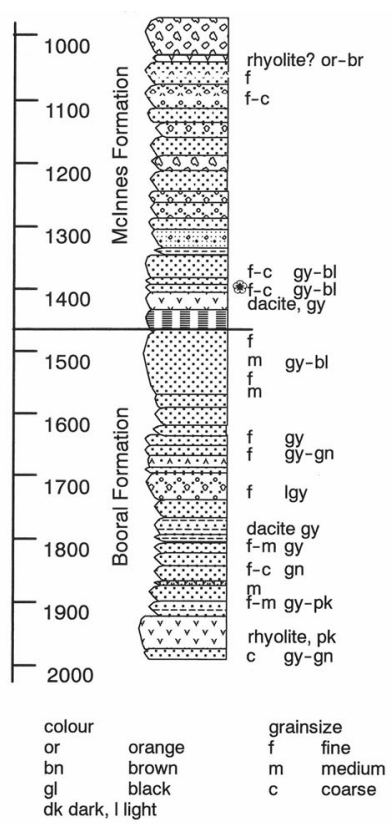

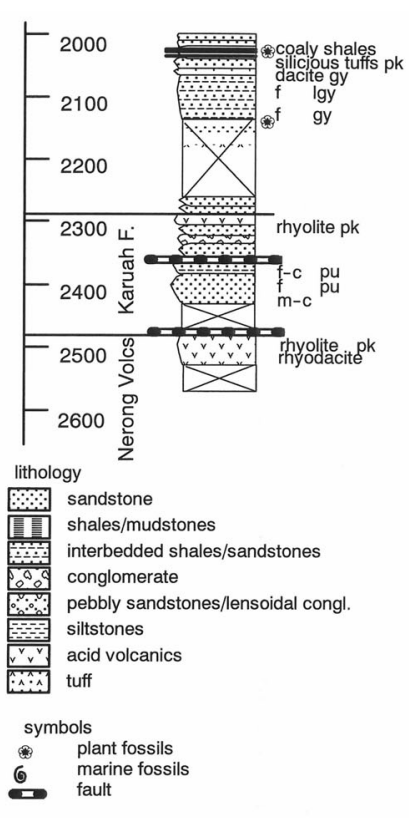

Fig. 2

Interpreted stratigraphic section and unit names for the Karuah Bypass Section (modified from Fityus et al. 2005)

present within this formation are several volcanic units, consisting of pink and gray felsic ignimbrites. Beds within this formation yield a wide range of plant fossils (Rhacopteris ovata, Nothorhacopteris argentinica, Cyclostigma australe, Archaeocalamites radiatus) indicating an age between 325 to $298 \mathrm{Ma}$.

\section{McInnes Formation}

The base of the McInnes Formation is conformable with the Booral Formation, and is emplaced at a distinctive $33 \mathrm{~m}$-thick chert and sandstone bed, beneath a 25 $\mathrm{m}$-thick dacite unit. The top is taken to be a $100+\mathrm{m}$ sequence of bedded volcanics, comprising mostly flow-banded rhyolite and dacite, with some tendency to more mafic compositions in its upper part. The basal units of the formation are dominated by indurated, blue-gray, fine to medium-grained sandstone with uncommon coaly units. The central section consists of interbedded conglomerate, sandstone, shale and coal seams, up to a meter thick. The top $300 \mathrm{~m}$ consist of tuff, acid volcanic units and shale. Rhacopteris ovata is found in the two road cuts immediately east of the Karuah River, suggesting a similar age to that of the Booral Formation. Seat-earth (underclay) levels within the central section of the McInnes Formation suggest that it is of terrestrial origin. 
Johnsons Creek Conglomerate

The base of a $150 \mathrm{~m}$-thick section of boulder to pebble conglomerate was taken as the base of the $650 \mathrm{~m}$-thick Johnson's Creek Conglomerate, the clasts of which are predominately volcanic. This section is intercalated with thick beds of sandstone that are often bioturbated. The top of the formation was not observed but is supposed to coincide with the western interchange, possibly truncated by the Tarean Fault (discussed below). The section of strata between the Tarean Fault and the observed basal section of the Johnson's Creek Conglomerate is within a topographically low-lying and flat area that is deeply weathered, and that was not excavated. Bedrock was observed in only a few test pits.

Sructure

The general arrangement of the Karuah Bypass geology is shown in Fig. 3. Important aspects of the geologic structure of the area are the orientation of bedding and the widespread presence of jointing and faulting. A detailed structural analysis has not been undertaken, although sufficient observations are available to support a brief discussion. Figure 4 presents some limited bedding, jointing and faulting data from the area.

Bedding

The contoured equal area stereographic plot of poles in Fig. 4 gives a regional dip of the strata, striking $136^{\circ}$, dipping $25^{\circ}$ southwest. The plot is slightly scattered, suggesting that small variations occur between regions within the study area.

Jointing

Jointing is well developed within the area. A limited joint study within the McInnes Formation revealed three steeply dipping sets. One well-developed set strikes northwest-southeast, dipping up to $20^{\circ}$ in a direction between $020^{\circ}$ and $050^{\circ}$. Another prominent set strikes northeast-southwest, and is close to vertical. A third, less well developed, strikes close to north-south, close to vertical but with a slight dip in a direction just north of east. A fourth set with a north/south orientation occurs only sporadically in the study area (Fig. 4). These sets are similar to those recorded in a study of joints around the Williams River Fault by Offler (1996). The joints within the bypass area are believed to have been influenced by movement on the adjacent Tarean Fault.

Faulting

Major regional faults have been previously recognized at each end of the bypass. The western end is bounded by the north/south-trending Tarean Fault of Roberts et al. (1991). The presence of this fault is indicated by intense weathering which produces deep mottled clays (up to $10 \mathrm{~m}$ deep) in the region of the 
western interchange. The eastern end is cut by the northwesterly-trending Karuah fault zone (Morton 1999) that probably truncates the Karuah Formation. The Karuah Fault is manifested as an intensely brecciated zone, greater than 100 $\mathrm{m}$ wide, probably occurring mostly within the Nerong Volcanics.

The faults described above bound a block (see Fig. 3) in which the Bypass is mostly situated. This block is dissected by a number of significant, sub-parallel,

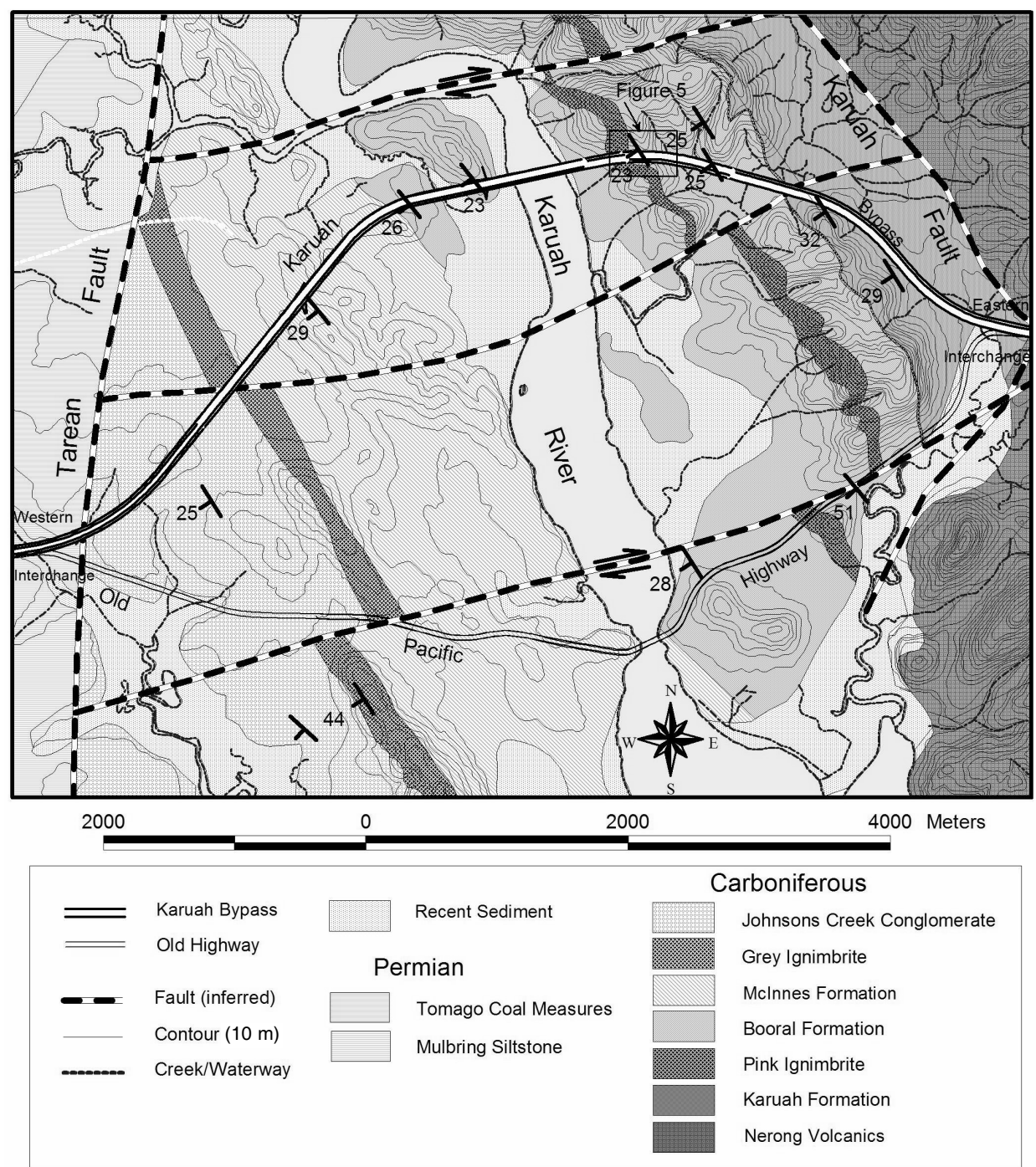

Fig. 3

Arrangement of geologic units and major structural features of the Karuah Bypass 


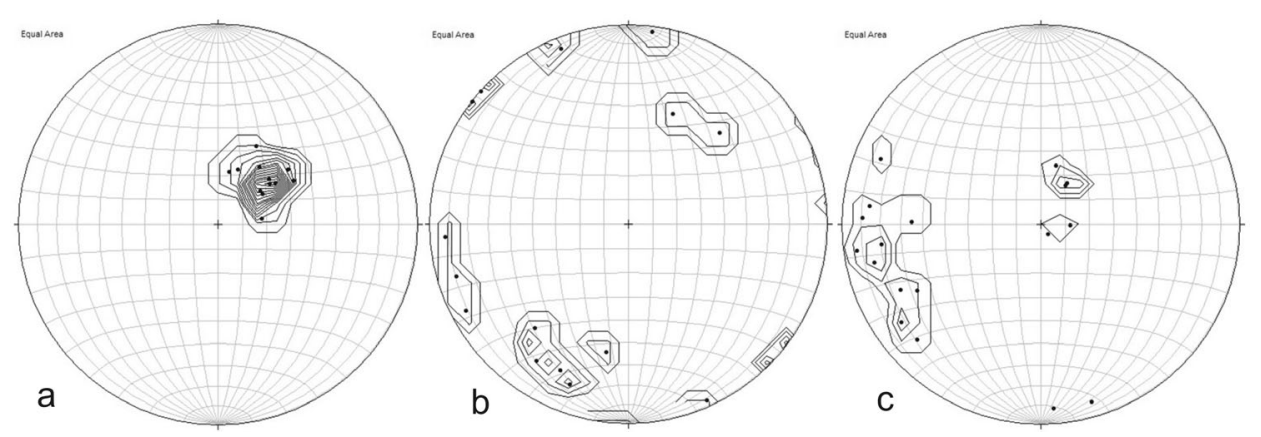

Fig. 4

Plots of structural data from the Karuah Bypass; a: poles to bedding planes; b: poles to joints; c: poles to fault planes

east-northeast trending faults. The relationship between the bounding faults and these dissecting faults, suggest that the dissecting faults might be secondary to the principal faulting. Their position and displacements, appearing in Fig. 3, have been inferred from displacements of marker beds, as revealed by regional mapping. The strike and dip-slip components of these faults could not be determined in this study. However, if strike-slip movement (as is evident from the jointing) is assumed, the movements are interpreted as predominantly dextral, with displacements of around 50-100 m.

Small displacement $(<1 \mathrm{~m})$, low-angle, thrust faulting was noted in several areas, and extensively developed within Cut 6 . These fault planes (Fig. 4) usually follow bedding planes, and are difficult to detect. Within the softer rocks of the McInnes Formation it is seen as fault-propagated micro-folding as the fault steps from one bed to the next, and it is highlighted by coal seams contained within the formation. Within the more indurated rocks of the Booral Formation, shearing along bedding planes is apparent through iron-stained, crushed zones up to 50 $\mathrm{mm}$ thick that frequently serve as sources of seepage. The most notable indication is displacement of the basalt dykes eastward by up to a meter (Fig. 5).

Smaller, sub-vertical faults occur in several cuts (Fig. 4). One set, examined in detail in Cut 6, formed a small graben several meters wide, with a vertical displacement of approximately $1 \mathrm{~m}$. It is evident from Fig. 4 that most of these smaller faults strike between north-south and northwest-southeast, similarly to joints shown in Fig. 4. The plunge of striations, observed on the surfaces of these faults, varies between 10 and 20 degrees, indicating a major strike-slip component in their movement.

It has been speculated (informally) that the Karuah River may have exploited a major fault in its formation. The fact that bedding orientation and regional mapping shows no displacement across the river, together with a lack of positive borehole indications within the river bed, suggests that the river did not make use of a major fault system. 

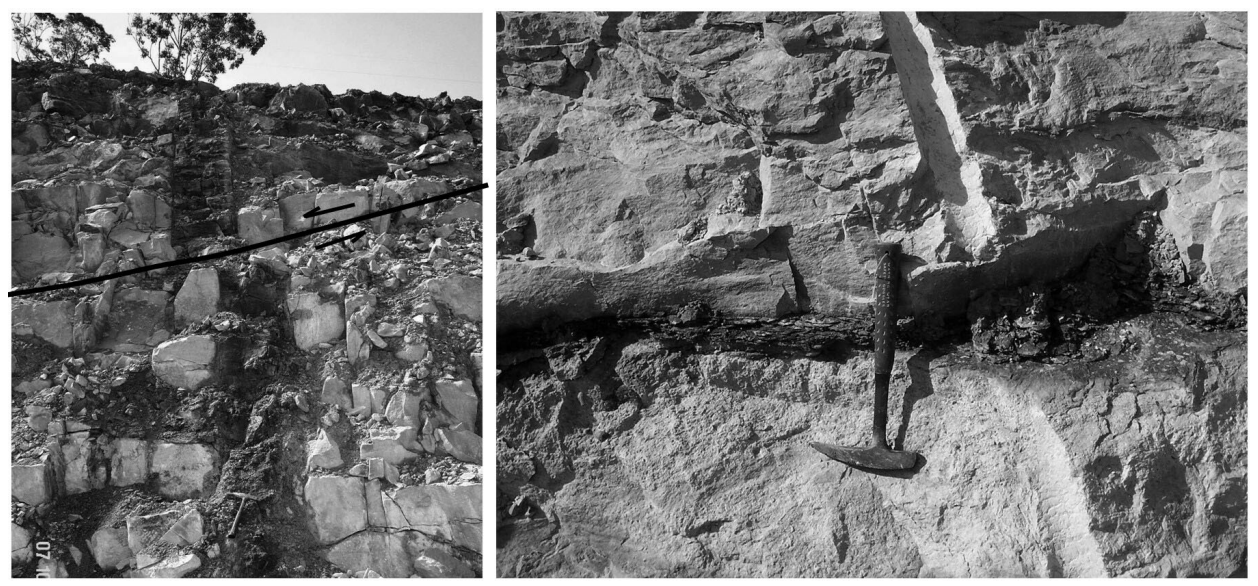

Fig. 5

Low-angle faulting, producing an offset in a basalt dyke (left picture), showing porous, iron-stained discontinuity in otherwise fresh rock (right picture)

\section{Dykes}

Thirteen sub-vertical, mafic dykes were encountered within road cuts to the east of the Karuah River. Ten dykes are in the large Cut 6 (immediately east of the river) whilst the remaining three are exposed in cuts further to the east. The dykes have two primary orientations: eight trend north/south $\left(175^{\circ}-355^{\circ}\right)$, dipping slightly to the east $\left(87^{\circ}-90^{\circ}\right)$, the remaining five trend northeast $\left(065^{\circ}-245^{\circ}\right)$ and are close to vertical. The orientation is similar to that of joints, shown in Fig 4. Within Cut 6, the northeast-trending "large" dykes are much thicker (3-6 m) than the north-south trending "small" dykes $(0.3-1 \mathrm{~m})$, and are more altered. The arrangement of dykes in Cut 6 is shown in Fig. 6. The northsouth dykes are composed of basalt of a common appearance. One of the thicker, northeasterly dykes is composed of fractured basalt, veined with secondary minerals. Another of the thick northeasterly dykes is composed of dolerite, and contains plagioclase and pyrite, with "clotted" plagioclase making up about $40 \%$ of the rock.

Selected chemical analysis results of six of the dykes within Cut 6 are shown in Fig. 7 and they suggest that the north-south and northeast groups have slightly different chemical compositions. Offler (2004, pers. com.) suggests that the northsouth dykes display calc-alkaline signatures, while the northeastern dykes show island-arc, tholeiitic signatures.

The most significant aspect of the dykes from an engineering perspective is their deep weathering and alteration, which was high to extreme at depths of up to 10 or $15 \mathrm{~m}$. In shallower situations, the extremely weathered dykes comprised wide, sub-vertical zones of weak, erodible material within jointed, thick beds of 
372 S. Fityus et al.

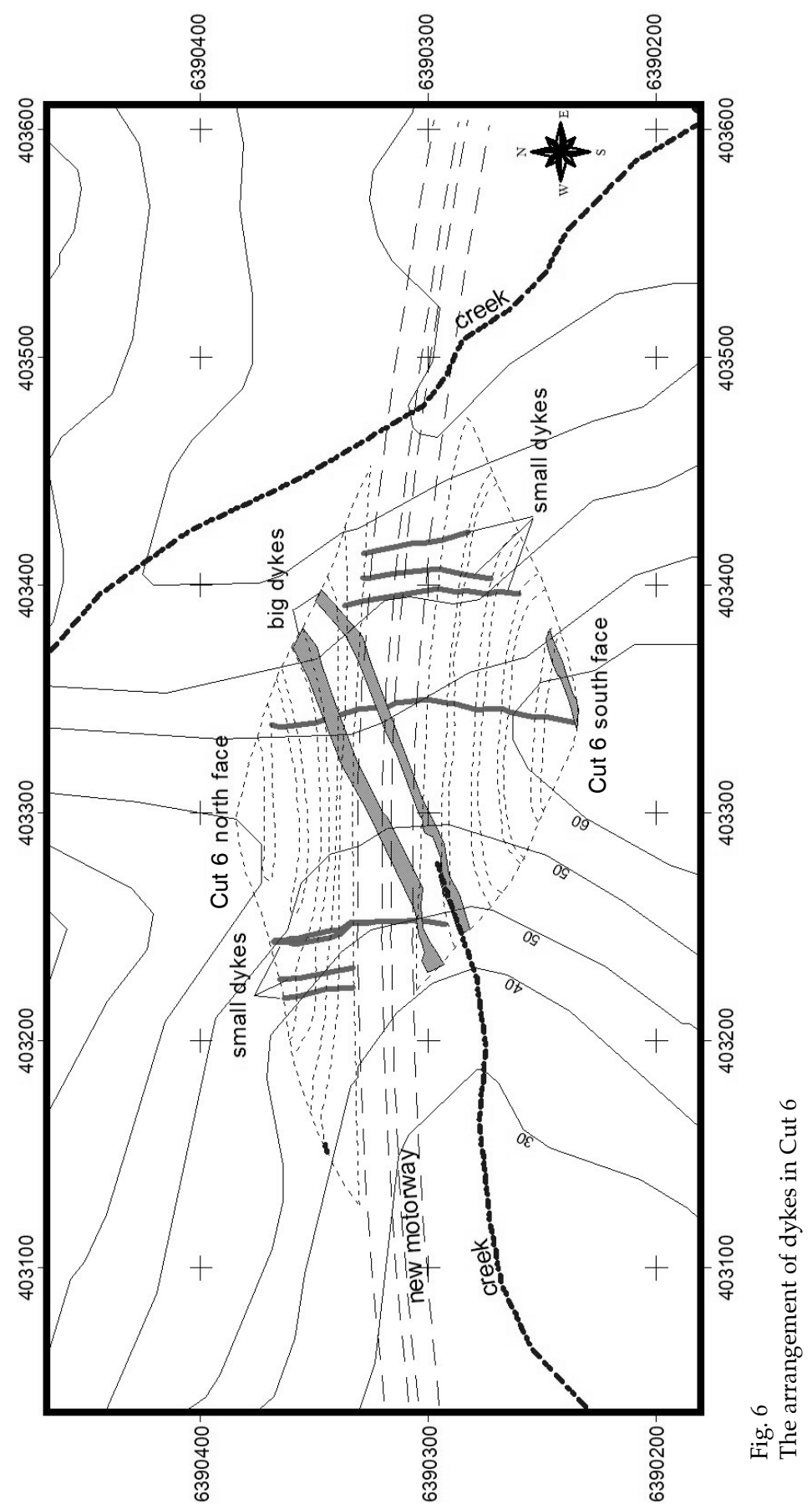

Central European Geology 50, 2007 

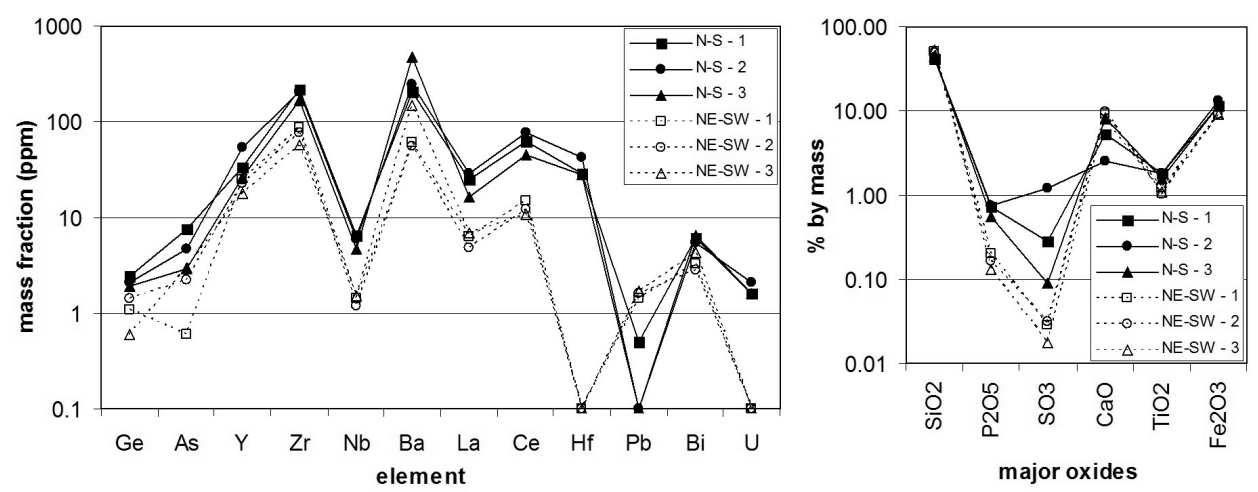

Fig. 7

Selected chemical analysis data for three basalt samples from the north-south dykes (N-S) and three samples from the north-east dykes (NE-SW)

more competent material. In this context they exhibit great potential to become eroded, leaving rock masses unsupported, and hence prone to collapse/toppling. As such, in most instances, they required shotcreting soon after exposure.

\section{Consequences}

Weathering and rock strength

The structural features of the Karuah Bypass geology have some significant consequences for the distribution of soils and weathering across the site. Faulting, in particular, has a profound effect on the rate of depth of weathering, giving the region a distinctive geomorphology.

Major faults are commonplace within the southern NEFB, dividing it into blocks within which geologic conditions are relatively constant. However, across these faults, the stratigraphy and structure may change dramatically. These major faults may affect zones that are tens or hundreds of meters wide, and they may be traced for many tens of kilometers. Major faults of this type bound the ends of the Karuah Bypass. They are shown as the Tarean and Karuah Faults in Fig. 3. In each location these faults have produced wide, fractured and deeply weathered zones. At the western end, excavation and replacement of 6 to $8 \mathrm{~m}$ of weathered material due to the Tarean Fault was undertaken to improve founding conditions for the western interchange. At the eastern end (Fig. 8), fractured and deeply weathered volcanic rocks were encountered over a width of at least $200 \mathrm{~m}$ in a cut through the Karuah Fault, where the bypass ties into the existing highway.

There is no evidence to suggest that any other major faults exist in the geologic interval between the Tarean and Karuah Faults. However, there are several significant faults in this interval that displace the stratigraphy by as much as hundreds of meters without producing any significant rotation of the beds across 


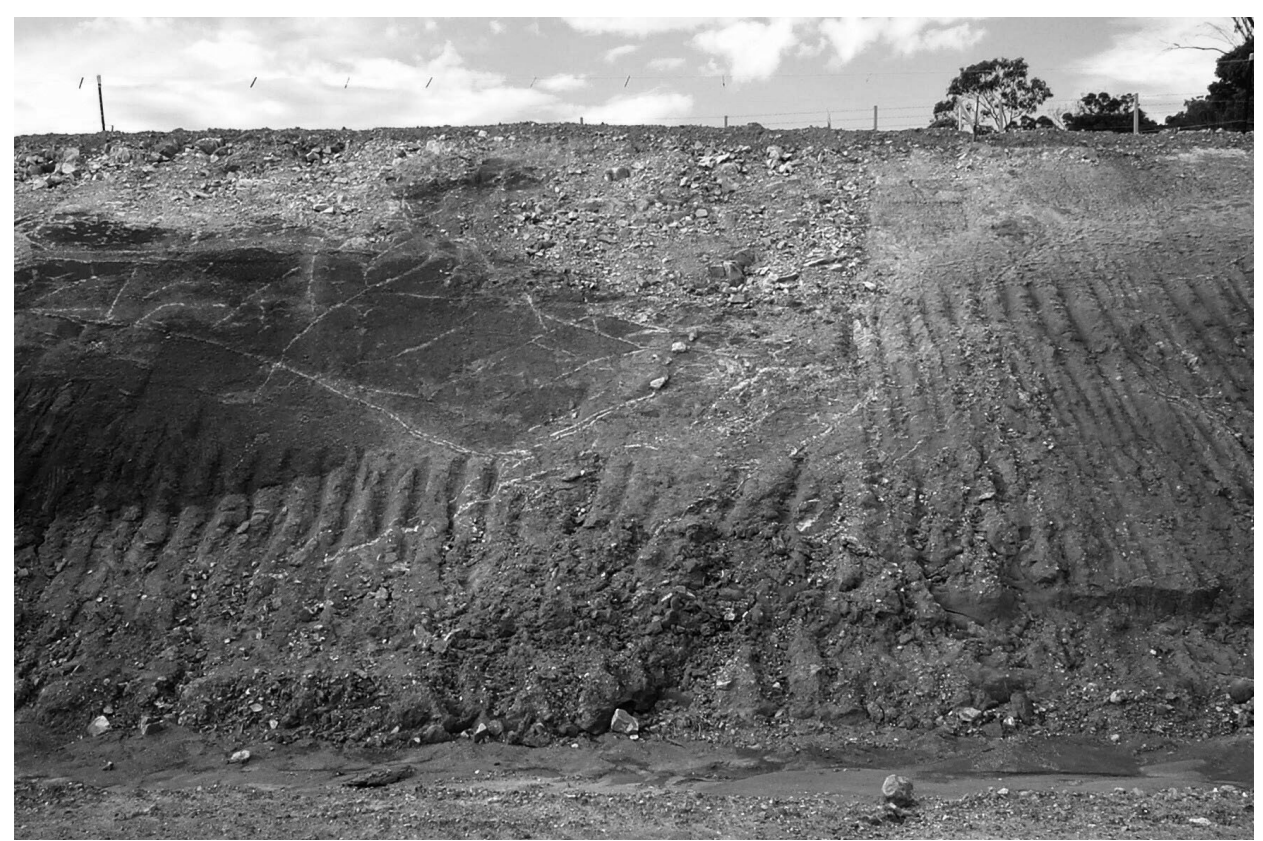

Fig. 8

Photographic compilation of fault-affected rocks and soils at the eastern end of the Karuah Bypass, showing the Karuah Fault

the fault. These faults also affect the integrity of the geology over significant widths, although this is seldom observed in excavations or exposures. In fact their presence is only inferred from displacements in marker beds, which occur on either side of deeply weathered, sediment-filled topographic lows.

The sequence of interbedded softer sediments and harder felsic volcanics gives rise to a general trend of parallel ridges with uniform slopes and narrow crests capped with the harder volcanics. The weathering associated with the many significant faults that cut across the stratigraphy has focused erosion, truncating many of these ridges with deeply incised drainage lines. The result is a topography of sharp-topped, elongated hills with parallel axes. The engineering significance of this is that the depth of weathering is variable, and there are no clear trends in rock quality and strength as a function of depth.

Figure 9 presents data on rock strength as a function of rock type and depth. Although there is a weak trend for average rock strengths to increase with increasing depth, rock strengths are still widely scattered at more than $25 \mathrm{~m}$, and this includes results for naturally stronger materials such as dacite and crystal tuff. This variability is a consequence of the variable effects of weathering that result from faulting and other factors. Nevertheless it is important to note that the range of strength is probably greater than shown in Fig. 9, since more competent 


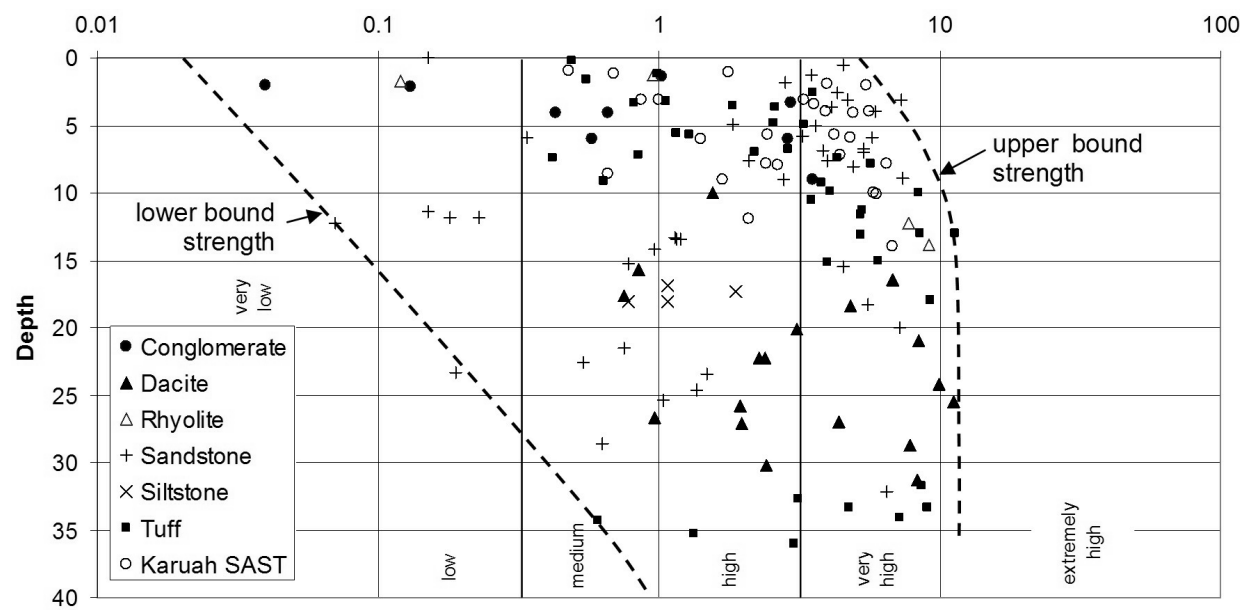

Fig. 9

Rock strength as a function of type and depth for the Karuah Bypass

rocks are over-represented, due to the fact that low strength fractured zones are difficult to detect because of sample size and test method.

Figure 9 indicates that several of the different rock types exhibit great strength at relatively shallow depth. In general the clastic sedimentary rocks exhibit varying strength, and these include the weakest rocks encountered, with sandstone in some cases possessing only low to medium strength at depths as great as $20-25 \mathrm{~m}$. Tuffaceous rocks generally possess medium to very high strength, being mostly of high to very high strength at depths greater than about $10 \mathrm{~m}$. Felsic volcanics mostly possess high to very high strengths; however, despite extensive, well-developed surface expression in adjacent areas, almost no volcanics were encountered within $5 \mathrm{~m}$ of the surface during the initial site investigation. The relatively tuffaceous, characteristically purple, Karuah sandstone possesses high to very high strength at shallow levels (as shallow as $2-3 \mathrm{~m}$ ), consistent with its strong outcropping tendencies at the eastern end of the section.

One factor affecting weathering, not yet discussed, is the occurrence of the mafic dykes. These exhibit a tendency to weather preferentially and deeply under the prevailing conditions, so that they produce pockets of deep soil in otherwise competent rocks. Figure 10 shows three narrow dykes in Cut 6. Note how, adjacent to the one to the right, the rock mass has become preferentially fractured and weathered for a considerable depth below the surface. Figure 10 also displays how the dyke materially weathers preferentially, relative to the sandstone into which it was emplaced. 

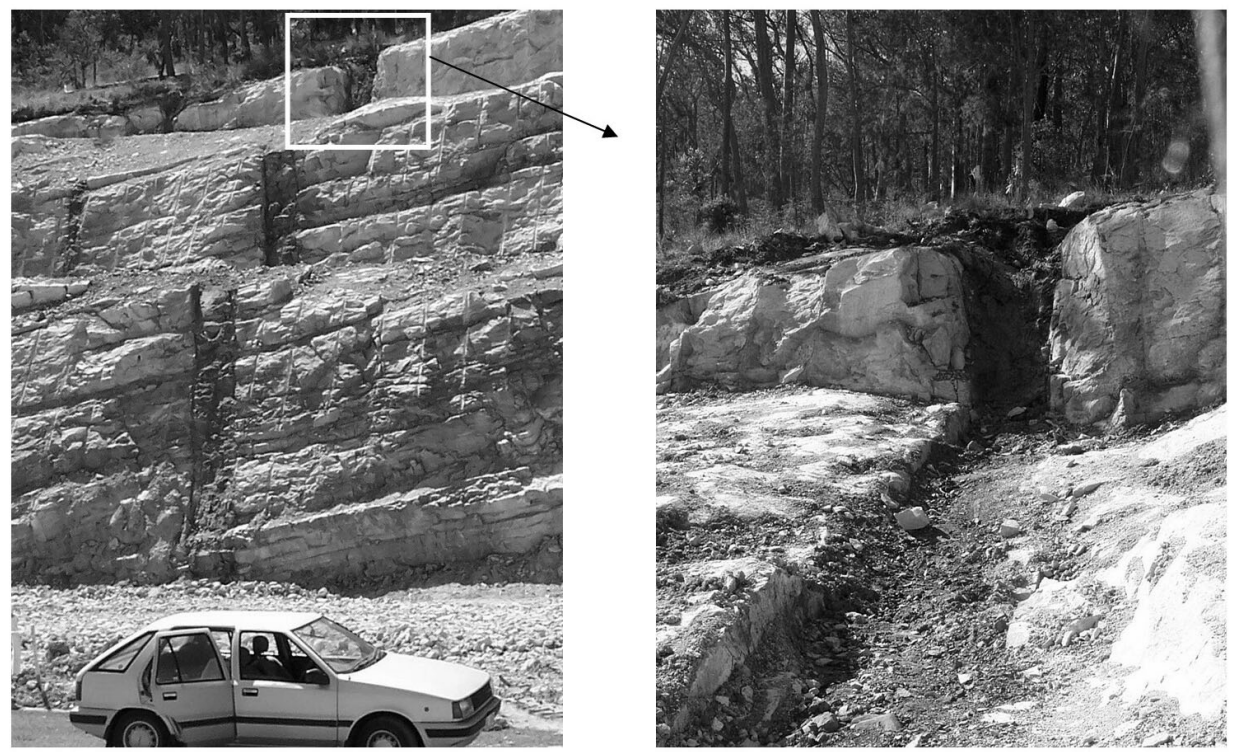

Fig. 10

Expressions of weathered mafic dykes in excavation (on the left a north-south dyke in road cut 6, on the right a close up view shows the preferential weathering in the upper part of the dyke zone)

\section{Excavation and slope stability}

As noted previously, the structural characteristics of rocks in the Bypass include shallow dipping beds, persistent jointing in several directions and localized faulting. These combine in various ways to affect rock mass characteristics. Most notably, the dip of the sedimentary beds leads to the potential for block sliding, where the alignment of road cuts is close to geologic strike. For dips of around $28^{\circ}$ or less that occur along the bypass, block sliding analyses indicate that sliding on bedding planes is unlikely to occur (SMEC 2002). However, due to the relatively high strength of the fresher rocks, drilling and blasting was required in most of the cuts, and as a consequence significant loosening of the strata occurred in some areas. There is some evidence to suggest that some of the bedded sandstone in the Booral Formation (Cut 6) is particularly prone to bedding plane separation upon unloading. In some cases relatively thick sandstone units in the base of deeper cuts are observed to separate into numerous, distinct thinner beds as they are traced up-dip toward the ground surface. 
The low-angle faulting, which is mostly parallel, or sub-parallel to bedding, is an important factor that exacerbates the loosening and sliding of potentially unstable blocks (see Fig. 5). This conclusion differs from that of Fityus et al. (2005), being modified to accommodate new experiences with such faulting gained in similarly deformed rocks in other areas. It is difficult to evaluate how extensive this low-angle faulting is, as its displacement is small and usually confined to the bedding planes. However, from the widespread bedding-plane seepage in some exposures of apparently fresh rock (Fig. 11), it would seem that rockmass disruption at bedding plane surfaces is a pervasive feature of this geologic environment.

Bedding dips of $20^{\circ}$ to $30^{\circ}$ are particularly problematic. They become steep enough that spontaneous sliding of detached blocks might occur. However, intrinsic stability can only be achieved when excavation faces are battered back to the same angle as bedding; for deeper excavations, battering to less than $30^{\circ}$ requires substantial volumes of excavation. If the volumes excavated are to be limited, then cut faces must be steepened in excess of the bedding slope. Where the strike of the bedding and direction of excavation faces are close to parallel, this leads to a situation where bedding planes "daylight" into the excavation, producing potentially unstable material. The presence of daylighting bedding planes alone is insufficient to allow sliding. However, well-developed jointing in 3 or 4 different directions transforms the beds of rock into blocks of rock, giving them the potential to be released from the rock mass.

In the situation of Cut 6 on the Karuah Bypass, bedding strike was $145^{\circ}-325^{\circ}$ (dipping $23^{\circ}$ to the southwest), whilst the axis of the $30 \mathrm{~m}$-deep cut was aligned in a direction close to east-west. On the southern face of the cut bedding dipped back into the excavated face, and so regardless of the steepness of the excavation it was intrinsically stable against failure by sliding along bedding. However, the excavation slope was limited to $1 \mathrm{H}: 1 \mathrm{~V}\left(45^{\circ}\right)$, since the set of joints dipping to the northeast at angles as low as $60^{\circ}$ were considered likely to affect stability and have maintenance implications.

For the northern face of the cut, which slopes to the south, an intrinsically stable arrangement would require batter slopes as low as $15^{\circ}$, allowing for the effects of apparent dip. As this was clearly a non-feasible option for a $30 \mathrm{~m}$-deep cut, the adopted strategy was to excavate a series of steeper faces separated by regular horizontal benches. The potentially loose blocks so formed (Fig. 11) were then treated, either by removal or by the installation of strategically positioned anchors. Since potentially unstable blocks are created as soon as the excavation becomes steeper than the bedding, it was decided that batter slopes should be steepened to between $0.5 \mathrm{H}: 1 \mathrm{~V}\left(63^{\circ}\right)$ and $1 \mathrm{H}: 1 \mathrm{~V}\left(45^{\circ}\right)$ to reduce the size and number of potentially unstable blocks that would need to be stabilized, and to limit the amount of maintenance (such as scaling and bolting) over the life of the road.

In one location, in a sequence of thinly-bedded siltstone and fine sandstone, the intersection of a dipping bed $202^{\circ} / 25^{\circ}$ and another planar feature $097^{\circ} / 62^{\circ}$ 

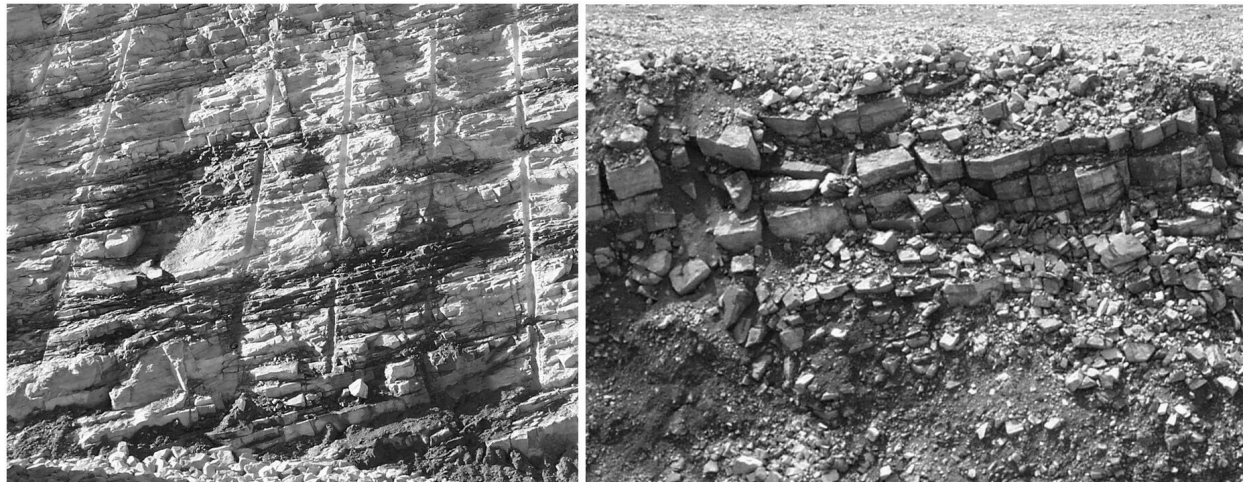

Fig. 11

Bedding plane features. Left picture shows seepage (darker areas) from bedding plane surfaces in fresh rock. Right picture shows the unfavorable relationship between bedding planes and excavation surfaces, leading to looseness and instability

produced a triangular wedge, extending over the full height of an $8 \mathrm{~m}$-high cutting. This wedge failed spectacularly in a V-slide as is shown in Fig. 12, after a small quantity of soil was stockpiled on top of the cutting.

If the poles to the failure planes of the V-slide are plotted together with the poles to small faults and bedding (Fig. 13), it is clear that the block failure was controlled by faulting and bedding. Note, however, that the plane close to

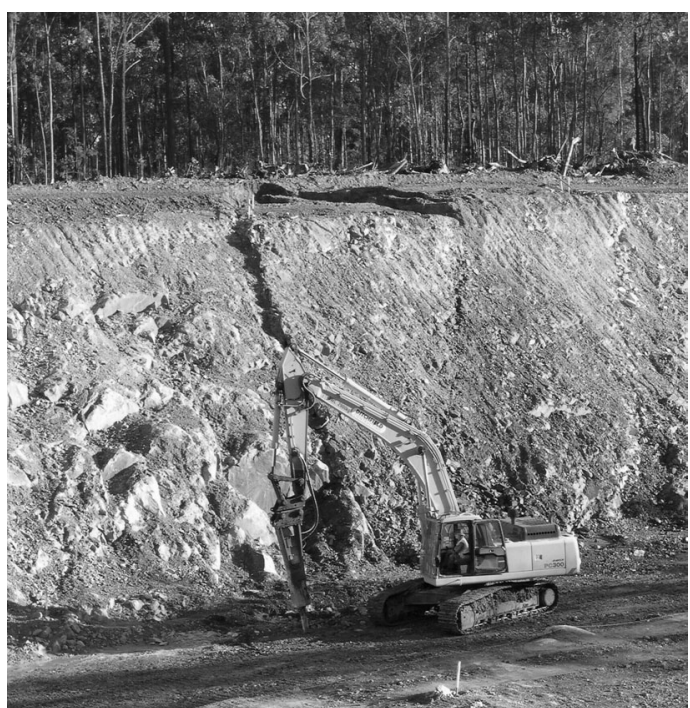

Fig. 12

A V-slide wedge failure in thinly-bedded siltstone and fine sandstone bedding (Fig. 13) also plots with the low-angle faults in Fig. 13, suggesting that the role of bedding may be somewhat indirect, and that small-scale faulting of two types may have been the dominant influence.

\section{Conclusions}

Mildly deformed sedimentary strata often display extensively developed rotation of strata and pervasive jointing. This makes slopes in such geologic environments prone to instability through bedding plane sliding, and makes road cut stability a major engineering consideration. In the case of the Karuah Bypass, the presence of faulting at many 

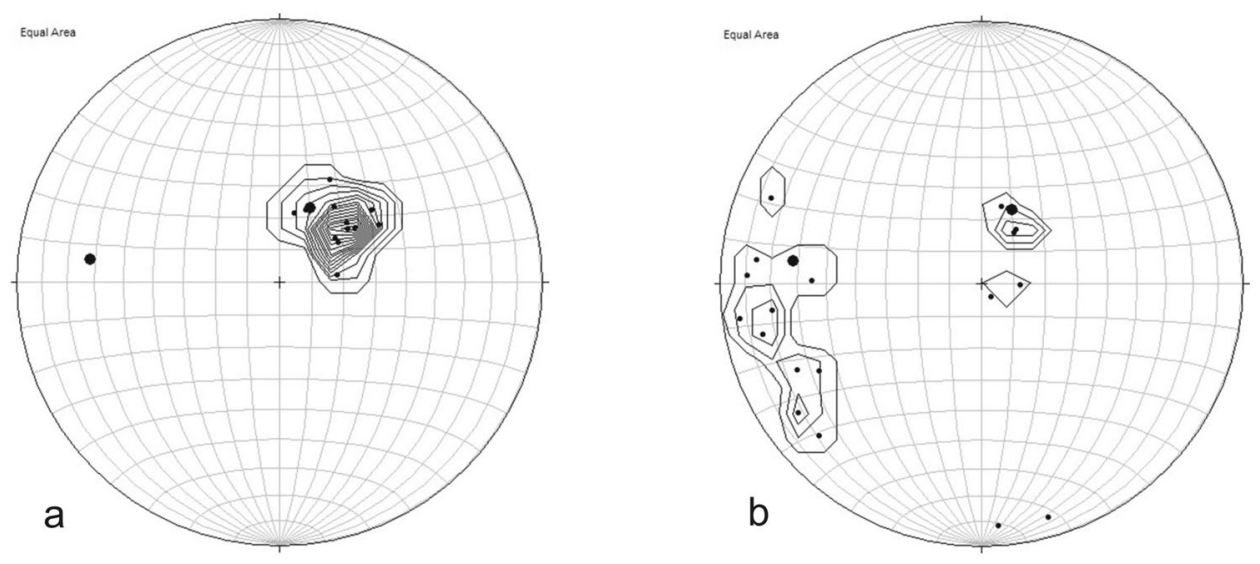

Fig. 13

Relationship of V-slide failure planes to bedding and faulting; a: stereographic plot shows poles of planes in V-slide (large points) superimposed onto bedding plane poles; b: stereographic plot shows poles of planes in V-slide (large points) superimposed on poles to small faults

scales has produced a situation where interactions between many different geologic surfaces can lead to several different rock-mass behaviors. In particular, low-angle bedding plane faulting throughout the rock-mass has significantly changed the basic mechanical behavior. These faults accommodate seepage, promote rock-mass looseness and exacerbate sliding. Their presence is significant for situations where drilling and blasting is considered as a means of controlling rock-mass excavation, as they are observed to be adversely affected by the energy imparted by blasting.

Detection of the low-angle faulting along bedding is problematic, particularly in the site investigation phase of projects in these geologic environments. In drill cores through thicker units, low-angle fault planes may appear as weathered seams or joints, if the orientation of the core is not known. There may be some benefit in making efforts to orient drill cores taken from boreholes, or to undertake geophysical logging of the boreholes to characterize the orientation of low-angle rock-mass defects.

The combination of multi-scale faulting and mafic dykes also has a significant effect on rock-mass quality and strength, with considerable rock strength variations observed to depths up to $25 \mathrm{~m}$. These result from the preferential chemical weathering of the dykes and the adjacent rock mass, and from accelerated weathering of the disrupted rock fabric in the vicinity of the faults, which may be of considerable extent.

The study of the Karuah Bypass illustrates the importance of a high-quality geologic investigation. Relatively subtle features such as bedding plane faults are easily overlooked in the investigation and planning stage of major projects, but their presence can significantly affect the response of the excavated rock mass 
during construction. Where such features are known to exist, there may be merit in choosing alignments or designing excavations to achieve inherent stability, so that the costs of stabilization and maintenance are reduced.

\section{Acknowledgements}

The authors would like to acknowledge the University of Newcastle and the Hungarian Academy of Sciences for facilitating the international collaboration to make this paper possible, and David Bax and Theiss Contractors in Australia for providing access to the Karuah Bypass during its construction. The informed reviews of this paper by Mr Mark Delaney and Dr. Pál Kertész are also greatly appreciated.

\section{References}

ARUP 1999: Pacific Highway Upgrade, Karuah. Concept Design and EIS. - Report 9809/510 Arup Geotechnics Pty. Ltd. Volumes 1-5.

Carey, S.W., W.R. Browne 1938: Review of the Carboniferous stratigraphy. Tectonics and palaeogeography of N. S. W. and Queensland. - Journal of the Royal Society of N. S. W., 17, 591 p. (Cited in Engel 1966).

Engel, B.E. 1966: 1: 250,000 Geological Series Map of Newcastle and Explanatory Notes. - Dept. mines Geological Survey of N. S. W. Sydney.

Fityus, S., J. Gibson, D. Bax, T. Rannard 2005: The Karuah Bypass: A case study in the engineering geology of the southern New England Fold Belt. - Australian Geomechanics, 40/2, pp. 43-54.

GSNSW 2003: Statewide Geology of NSW (1:250,000 GIS compilation) Geological Survey of New South Wales. - Department of Mineral Resources. NSW.

Korsch, R.J., H.J. Harrington 1981: Stratigraphic and structural synthesis of the New England Orogen. - Geological Society of Australia, 28, pp 205-226.

Morton, S. 1999: Some trends noted in the Nerong Volcanics, north of Karuah. - Proceedings of the Thirty Third Newcastle Symposium on Advances in the Study of the Sydney Basin. Newcastle University.

Murray, C.G. 1997: From geosyncline to fold belt: a personal perspective on the development of ideas regarding the tectonic evolution of the New England Orogen. - In: Ashley, P.M., P.G. Flood (Eds): Tectonics and Metallogenics of the New England Orogen. Geological Society of Aust. Special Publication, No 19, pp. 1-28.

Offler, R. 1996: Kinematic history of the Williams River Fault - A major suture in the Southern New England Fold Belt. - In: Boyd, R.L., G.A. MacKenzie (Eds): Proceedings of the 30th Newcastle Symposium, Advances of the Sydney Basin, University of Newcastle, Newcastle, pp. 105-112.

Roberts, J., B. Engel, J. Chapman 1991: Geology of the Camberwell, Dungog, and Bulahdelah 1: 100,000 Sheets. - Geological Survey of N.S.W. Dept. Min. Res. Sydney.

Schreiber, E. 1998: Geology of New South Wales - Syntheses. Vols 1, 2. In: Basden, H. (Ed.) Geological Survey of NSW - Memoir No. 13/2, Dept. Min. Res., Sydney.

SMEC 2002: Preliminary Geotechnical Investigation for the proposed Karuah Bypass. - Snowy Mountains Engineering Corporation P/L. Sydney. (unpublished).

Voisey, A.H. 1959: Australian Geosynclines. - Australian Journal of Science, 22, pp. 188-198. 